\title{
Desempenho agronômico de linhagens de trigo em diferentes ambientes no Sudoeste paulista
}

\author{
Allan Henrique da Silva $\left({ }^{*}\right)$; Carlos Eduardo de Oliveira Camargo $(2,3)$; \\ Antonio Wilson Penteado Ferreira Filho $\left({ }^{3}\right)$; João Carlos Felício $\left({ }^{3}\right)$; Edison Ulisses Ramos Júnior $\left({ }^{4}\right)$ \\ (') Instituto Agronômico (IAC), Programa de Pós-Graduação em Agricultura Tropical e Subtropical, 13012-970 Campinas (SP). \\ (2) In memoriam. \\ (3) IAC, Centro de Análise e Pesquisa Tecnológica do Agronegócio de Grãos e Fibras, Caixa Postal 28, 13012-970 Campinas (SP). \\ (4) APTA, Polo Regional do Desenvolvimento Tecnológico dos Agronegócios do Sudoeste Paulista, Caixa Postal 62, $18300-970$ \\ Capão Bonito (SP). \\ (*) Autor correspondente: allanhenrique_agron@yahoo.com.br
}

Recebido: 1.\%/fev./2009; Aceito: 1.\%/nov./2010.

Resumo

O objetivo desse estudo foi avaliar a adaptabilidade e estabilidade de 18 linhagens e duas cultivares de trigo quanto à produção de grãos, altura de plantas, tolerância ao alumínio $\left.(A)^{3+}\right)$ e outros caracteres em experimentos instalados em solos ácidos e corrigidos, no período de 2006 a 2008. Nas linhagens 13 e 17, tolerantes a 8 e 10 mg L-1 de Al ${ }^{3+}$, observaram-se adaptabilidade e estabilidade ampla para produção de grãos, maior massa de cem grãos e resistência ao acamamento. A cultivar IAC-370 e a linhagem 6, tolerantes a 4 e $8 \mathrm{mg} \mathrm{L}^{-1}$ de $\mathrm{Al}^{3+}$, foram responsivas à melhoria do ambiente. A linhagem 20 , tolerante a $10 \mathrm{mg} \mathrm{L}^{-1}$ de $\mathrm{Al}^{3+}$, revelou adaptação a ambientes desfavoráveis e maior número de espiguetas por espiga. As linhagens exibiram porte semianão com exceção da linhagem 3 (porte anão). Foram identificados genótipos superiores para resistência à ferrugem-da-folha (linhagem 12), número de espiguetas e de grãos por espiga (linhagem 15), comprimento de espigas (linhagens 5 e 8) e número de grãos por espigueta (linhagem 18). Houve tendência de os genótipos mais produtivos ficarem com porte semianão mais alto e grãos mais pesados em solo ácido e corrigido. Os genótipos mais tolerantes na presença de 2 a $6 \mathrm{mg} \mathrm{L}^{-1}$ de $\mathrm{Al}^{3+}$, em solução nutritiva, foram os mais produtivos em solo ácido.

Palavras-chave: Triticum aestivum L., produção de grãos, adaptabilidade e estabilidade, tolerância à toxicidade ao alumínio.

\section{Agronomic behavior of wheat inbred lines in different environments in southwest of Sao Paulo State}

\begin{abstract}
The objective of this study was to evaluate the adaptability and stability of 18 wheat inbred lines and two wheat cultivars (control) to grain yield, plant height, tolerance to aluminum and other characteristics in experiments carried out in acid soil and limed soil conditions, in 2006-2008. The lines 13 and 17, tolerant at 8 and $10 \mathrm{mg} \mathrm{L}^{-1}$ de Al ${ }^{3+}$, showed high adaptability and stability to grain yield, heavy grains and resistance to lodging. The cultivar IAC-370 and the line 6 , tolerant to 4 and 8 mg

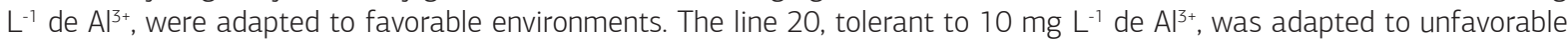
environments and showed good performance for number of spikelets per spike. All lines showed semi-dwarf plant, except the line 3 (dwarf). Superior genotypes were identified to leaf rust resistance (line 12), number of spikelets per spike and grains per spike (line 15), head length (lines 5 and 8) and grains per spikelet (line 18). The most productive genotypes tend to show taller semi-dwarf plant types and heavier grains in acid soil and limed soil condition. The most tolerant genotypes to 2 and 6 $\mathrm{mg} \mathrm{L}^{-1}$ de $\mathrm{Al}^{3+}$ in nutrient solution were the most productive in acid soil.
\end{abstract}

Key words: Triticum aestivum L., grain yield, adaptability and stability, tolerance to aluminum toxicity. 


\section{INTRODUÇÃO}

O aumento das pesquisas no melhoramento genético de trigo no Estado de São Paulo tem permitido o avanço da cultura em diferentes condiçóes edafoclimáticas associadas a diferentes sistemas de manejo. Entretanto, há necessidade, ainda, de muita pesquisa visando ao aumento da produtividade e redução dos custos de produção, principalmente em relação aos defensivos e corretivos agrícolas (CAmargo et al., 2008).

O programa de melhoramento genético de trigo do Instituto Agronômico (IAC), por meio de hibridações entre cultivares e genótipos submetidos à irradiação gama com linhagens introduzidas do Centro Internacional de Melhoramento de Milho e Trigo (CIMMYT), México, seguidas de seleções, resultaram na obtenção de linhagens com maior produtividade, porte semianão, resistência a doenças e tolerância à toxicidade de alumínio (CAMARgo et al., 1995; Tulmann Netto et al., 2001; Camargo et al., 2005).

A expressão de um determinado fenótipo resulta da ação conjunta do genótipo, do ambiente e da interação entre o genótipo e o ambiente (Allard, 1999). A interação reflete as diferentes respostas dos genótipos às variaçôes ambientais, resultando em mudanças no seu desempenho relativo (Falconer e Makay, 1996).

O método proposto por Lin e Binns (1988), com as modificaçóes propostas por CARNeIro (1998), tem sido

Tabela 1. Genealogia dos genótipos de trigo comum avaliados em Capão Bonito, em condição de solo corrigido e solo ácido, nos anos de 2006 a 2008

\begin{tabular}{|c|c|}
\hline Tratamentos & Genealogia \\
\hline 1 & $\begin{array}{l}\text { IAC-24 (IAS-51/4/SON64/Y50E//GTO/3/2*CNO) = } \\
\text { Testemunha }\end{array}$ \\
\hline 2 & $\begin{array}{l}\text { IAC-370 }(\mathrm{BOW} / / \mathrm{NAC} / \mathrm{VEE} / 3 / \mathrm{BJY} / \mathrm{COC})= \\
\text { Testemunha }\end{array}$ \\
\hline 3 & IAS-63/ALDAN“S”//GLEN/3/IAC-24/4/IAC-24 \\
\hline 4 & URES81/4/CAL/WRAM//WS1657/3/ANA/5/IAC-24 \\
\hline 5 & $\begin{array}{l}\text { THB/5/ALD/3/FKN/H570.71//FKN/4/MAD/CNT7... } \\
\text { /6/BH-1146 M }\end{array}$ \\
\hline 6 & UP2338-OIND//ANA $\mathrm{M}_{3}$ \\
\hline 7 & $\begin{array}{l}\text { COOK/VEE“S”//DOVE“S”/SERI/3/IAC-24/4/BH- } \\
1146 \mathrm{M}_{2}\end{array}$ \\
\hline 8 & ALDAN“S”/IAS-58//IAC-24/3/BH-1146 M \\
\hline 9 & JUN“S”/IAC-60//BH-1146 M \\
\hline 10 & IAC-352/BH-1146 M \\
\hline 11 & IAC-352/BH-1146 M \\
\hline 12 & MON“S”/ALD“S”//IAC-24/3/BH-1146 M \\
\hline 13 & MON“S”/ALD“S”//IAC-24/3/BH-1146 M \\
\hline 14 & IAC-350/BH-1146 $\mathrm{M}_{2}$ \\
\hline 15 & CAL/CHKW/VEE“S”//BH-1146 M \\
\hline 16 & $\begin{array}{l}\text { THB/5/ALD/3/FKN/H570.71//FKN/4/MAD/CNT7... } \\
\text { /6/BH-1146 } \mathrm{M}_{2}\end{array}$ \\
\hline 17 & MON“S”/ALD“S”//IAC-24/3/IAC-350 \\
\hline 18 & KAUZ“S”/IAC-24//IAC-289 \\
\hline 19 & KAUZ“S”/IAC-24//BH-1146 M \\
\hline 20 & KAUZ“S”/IAC-24//BH-1146 M \\
\hline
\end{tabular}

constantemente utilizado visando identificar genótipos de trigo com adaptabilidade e estabilidade para produção de grãos em ambientes favoráveis e desfavoráveis (AMORIN et al., 2006; Biudes et al., 2009).

Felício et al. (2001) demonstraram que linhagens de trigo e triticale cultivadas em Mococa, no período de 1996 a 1999, tiveram diferentes padrōes de resposta quando avaliadas no mesmo local, em ambientes favoráveis (irrigação por aspersão) e desfavoráveis (várzea irrigada por inundação).

A ferrugem-da-folha, causada pelo fungo Puccinia triticina Rob. ex Desm. f. sp.trititici, é uma das principais doenças que afetam a cultura do trigo, podendo ocorrer em diversas regióes tritícolas de diversos países, causando reduções significativas na produção de grãos, principalmente em anos favoráveis à sua ocorrência (CHAVEs e BARCellos, 2006; Barros et al., 2005). Diversos métodos de melhoramento, tais como hibridações com e sem irradiação (CAMARGo et al., 2005) e hibridaçóes interespecíficas (LoвAтo et al., 2007) têm sido utilizados com sucesso na obtenção de genótipos resistentes a esse patógeno.

O desenvolvimento de novas cultivares tolerantes ao alumínio, para cultivo em solos ácidos, tem sido apontado como uma das soluçóes mais promissoras no incremento da produção mundial de alimentos (KIm et al., 2001). O emprego de solução nutritiva tem sido uma ferramenta eficiente e precisa na seleção de plantas tolerantes ao alumínio (CAMARGO et al., 2006), pois aquelas com maior tolerância, em solução nutritiva, atingiram maior produção de grãos em solo ácido (CAMARGo et al., 2008), sem redução de potencial produtivo em solo corrigido (Rosa et al., 1994).

O objetivo deste trabalho foi avaliar o desempenho de linhagens quanto à produção de grấos, altura das plantas, acamamento, resistência à ferrugem-da-folha, comprimento da espiga e componentes da produçáo, em diferentes ambientes, além de estimar a adaptabilidade e estabilidade da produção de grãos e a associação com a tolerância ao $\mathrm{Al}^{3+}$ em solução nutritiva e outros caracteres estudados.

\section{MATERIAL E MÉTODOS}

Os experimentos foram instalados no município de Capão Bonito, São Paulo, (24 00' S, 48 $22^{\circ} \mathrm{W}$ e altitude $702 \mathrm{~m}$ ), região homogênea de adaptação II, em condição de sequeiro, em solo corrigido com calcário e em solo ácido, de 2006 a 2008.

Foram avaliadas 18 linhagens obtidas pelo programa de melhoramento de trigo do Instituto Agronômico (IAC) e duas cultivares controle IAC-24 e IAC-370 (Tabela 1). As linhagens foram obtidas por meio de hibridação entre cultivares nacionais adaptadas e linhagens introduzidas do Centro Internacional de Melhoramento de Milho e Trigo (CIMMYT), México. 
A cultivar IAC-24 utilizada como controle caracterizase pelo porte semianão, tolerância à toxicidade ao alumínio, média exigência em fertilidade do solo, média resposta à adubação nitrogenada e moderada suscetibilidade ao agente causal da ferrugem-da-folha. A cultivar IAC-370 foi introduzida pelo IAC através de uma coleção de linhagens, do CIMMYT e caracteriza-se pelo porte semianão, suscetibilidade à ferrugem-da-folha, resistência ao acamamento e moderada sensibilidade à toxicidade ao alumínio.

O delineamento utilizado em cada experimento foi o de blocos ao acaso, com quatro repetiçóes, totalizando 80 parcelas. Cada parcela foi formada por seis linhas de $3 \mathrm{~m}$, espaçadas por $0,20 \mathrm{~m}$ e separadas, lateralmente, por 0,60 $\mathrm{m}$. A semeadura foi feita utilizando-se 80 sementes viáveis por metro (1.440 sementes por parcela), com uma área útil de colheita de $3,6 \mathrm{~m}^{2}$.

Os dados de produçáo de grãos e ferrugem-da-folha foram obtidos no período de 2006 a 2008. A altura das plantas e o acamamento foram avaliados em de 2007 e 2008. Para estimar o comprimento da espiga, número de espiguetas por espiga, número de grãos por espiga e por espigueta e a massa de cem grãos foram tomadas cinco espigas de cada parcela. Para tanto, foram utilizados os experimentos instalados em 2008, em condição de solo corrigido e de solo ácido. Os dados obtidos nas 80 parcelas foram submetidos a análises individuais de variância, empregando-se o teste $\mathrm{F}$, ao nível de $5 \%$, para detectar efeitos significativos de genótipos e de blocos.

Efetuou-se uma análise de variância conjunta para rendimento de grãos dos seis experimentos para detectar efeitos de genótipos $(\mathrm{G})$, anos $(\mathrm{A})$, locais $(\mathrm{L})$ e das interaçôes GxA, GxL, AxL e GxAxL. O efeito de anos foi considerado como aleatório, assim como as interaçóes $\mathrm{GxA}$, AxL e a interação GxAxL. Os demais efeitos foram considerados fixos (Cruz et al., 2004). Para comparação das médias dos genótipos nos experimentos ou nos grupos de experimentos, empregou-se o teste de Tukey, ao nível de $5 \%$. Foram também realizadas análises conjuntas de variância para cada ambiente visando detectar a significância dos efeitos de anos, de genótipos e da interaçáo GxA para rendimento de grãos e altura das plantas.

Efetuou-se a estimativa dos parâmetros de adaptabilidade e estabilidade para produção de grãos, utilizando-se o método de Lin e Binns (1988) com as modificaçóes propostas por CARnEIRo (1998).

As análises de variância, os parâmetros de adaptabilidade e estabilidade foram estimados utilizando-se o programa GENES (Cruz, 2006).

Para testar a tolerância à toxicidade do alumínio, foram analisadas plântulas dos 20 genótipos e das cultivares controle BH-1146 (tolerante) e Anahuac (sensível), em condição de laboratório, nas doses de 0, 2, 4, 6, 8 e $10 \mathrm{mg} \mathrm{L}^{-1}$ de $\mathrm{Al}^{3+}$, empregando-se soluçóes nutritivas (CAMARGO et al., 2006).

$\mathrm{Na}$ análise dos dados, considerou-se a média do comprimento da raiz primária central das cinco plântulas de cada genótipo, para cada repetição. Após 48 horas nas soluçôes de tratamento contendo as diferentes concentrações de alumínio, os genótipos foram transferidos para soluçóes nutritivas completas sem alumínio por 72 horas. Aqueles que cresceram nesse meio foram considerados tolerantes; aqueles em que não houve crescimento das raízes foram considerados sensíveis.

Calcularam-se as correlaçôes simples para os experimentos instalados em Capão Bonito, em cada ambiente (solo corrigido e solo ácido), entre a produção de grãos e altura das plantas, comprimento da espiga e componentes da produção, considerando os dados obtidos nas 80 parcelas, em 2008. Foram também calculadas correlaçôes entre as produçôes médias de grãos, no período de 2006 a 2008, e os crescimentos médios das raízes das linhagens, medidas após 72 horas de crescimento na solução nutritiva, que se seguiu ao da solução tratamento contendo 2,4 , 6, 8 e $10 \mathrm{mg} \mathrm{L}^{-1}$ de $\mathrm{Al}^{3+}$.

\section{RESULTADOS E DISCUSSÃO}

A verificação prévia da homogeneidade dos resíduos das análises individuais de variância, através da relação entre o maior e o menor quadrado médio do resíduo (Tabela 2) permitiu a realização de análises conjuntas, cujos quadrados médios revelaram efeitos significativos para anos e para as interaçōes GxA, GxE, AxE e GxAxE. A significância das interaçôes GxA e GxE revelaram um padrão de resposta diferenciado dos genótipos em relaçáo aos anos e ambientes, considerados individualmente e também em conjunto (GxAxE), concordando com os dados obtidos por BIUDES et. al., 2009 e FeLício et al., 2001. Os dados obtidos no presente trabalho realçam a complexidade da interação entre o material genético estudado, em relação aos diferentes ambientes, mostrando a importância no manejo de

Tabela 2. Análise de variância conjunta para produção de grãos dos 20 genótipos de trigo avaliados em experimentos instalados em Capão Bonito, em condição de sequeiro em solo corrigido e em solo ácido, no período de 2006 a 2008

\begin{tabular}{lcrc|} 
Fontes de variação & $\begin{array}{c}\text { Graus de } \\
\text { liberdade }\end{array}$ & $\begin{array}{c}\text { Quadrados } \\
\text { médios (103) }\end{array}$ & F \\
\hline (Blocos/Ambiente)/Ano & 18 & 311,18 & \\
Genótipos (G) & 19 & 417,25 & 1,20 \\
\hline Anos (A) & 2 & $18.879,20$ & $60,67^{*}$ \\
\hline Ambientes (E) & 1 & $128.867,01$ & 8,91 \\
\hline G x A & 38 & 349,06 & $3,31^{*}$ \\
Gx E & 19 & 544,17 & $2,52^{*}$ \\
A x E & 2 & $14.455,60$ & $46,45^{*}$ \\
Gx A x E & 38 & 216,23 & $2,05^{*}$ \\
Resíduo & 342 & 105,52 & \\
Media & 1.524 & - & - \\
\hline C.V. (\%) & 21,32 & - & - \\
Maior QMR/menor QMR & 5,29 & & \\
\hline
\end{tabular}

* Significativo a $5 \%$ pelo teste $\mathrm{F}$. 
experimentos em diferentes anos e condiçôes de cultivos, proporcionando maiores informaçóes e confiabilidade na recomendaçáo dos genótipos mais promissores.

Os quadrados médios das análises de variância conjuntas, por ambiente, indicaram significância para genótipos (exceto em solo corrigido), anos e para interação genótipos $\mathrm{x}$ anos nos dois ambientes (Tabela 3). Considerando os dados individualmente, por ano, verificou-se que em Capão Bonito, em condição de solo corrigido, em de 2006, destacou-se a cultivar IAC-370 quanto à produção de grãos, com $3.552 \mathrm{~kg} \mathrm{ha}^{-1}$, náo diferindo das linhagens $3,6,11 \mathrm{e}$ 19 , com produtividade média de 2.788 a $3.160 \mathrm{~kg} \mathrm{ha}^{-1}$. Em 2007, a linhagem 17 proporcionou maior produção, com $2.868 \mathrm{~kg} \mathrm{ha}^{-1}$, diferindo apenas da linhagem 10 .

Nos experimentos instalados em condição de solo ácido, destacou-se a linhagem 19 com produtividade média de $1.285 \mathrm{~kg} \mathrm{ha}^{-1}$, em 2006, diferindo da cultivar IAC-370 e das linhagens 4, 14 e 18. Em 2007, sobressaiu-se a linhagem $17\left(1.715 \mathrm{~kg} \mathrm{ha}^{-1}\right)$, diferindo da cultivar IAC-370 e das linhagens 4 e 14 . A linhagem 20 exibiu maior produção de grãos em 2008 (1.444 $\left.\mathrm{kg} \mathrm{ha}^{-1}\right)$, diferindo da cultivar IAC-370 e das linhagens 3, 4, 6, 14 e 18 (Tabela 3).

Os resultados das análises de adaptabilidade e estabilidade para produção de grãos obtidos pelo método proposto por Lin e Binns (1988), com modificaçóes propostas por Carneiro (1998) estấo relacionados na tabela 4. Os experimentos foram classificados como favoráveis e desfavoráveis de acordo com o índice ambiental (I). Em 2006 ( $\mathrm{I}=1.022)$ e 2007 ( $\mathrm{I}=672$ ), em condiçáo de sequeiro e solo corrigido, os ambientes foram considerados favoráveis, mas em 2008 foi desfavorável (I=-139).

Os experimentos instalados no triênio em solo ácido foram classificados como desfavoráveis ( $\mathrm{I}=-670 \mathrm{em} 2006$, $\mathrm{I}=-231 \mathrm{em} 2007$ e I=-652 em 2008). As cinco melhores linhagens $(6,13,15,17$ e 19) se sobressaíram por possuírem maior adaptabilidade geral $\left(\mathrm{P}_{\mathrm{ig}}\right)$. De acordo com as modificaçóes sugeridas por CARNEIRo (1998), verificouse que a cultivar IAC-370 e as linhagens 3, 6, 13 e 17 foram mais responsivas quando o ambiente foi favorável $\left(\mathrm{P}_{\text {if }}\right)$ e as linhagens $9,12,13,17$ e 20 destacaram-se em ambiente desfavorável $\left(\mathrm{P}_{\mathrm{id}}\right)$.

Amorim et al. (2006) e Biudes et al. (2009), estudando diferentes métodos de adaptabilidade e estabilidade, relataram a eficiência do método Lin e Binns (1988), com modificaçôes propostas por CARNeIRo (1998) na identificação de genótipos de trigo mais adaptados e estáveis em diferentes ambientes.

A significância dos quadrados médios das análises de variância conjuntas para altura das plantas, avaliadas em solo corrigido e solo ácido, em Capão Bonito, em 2007

Tabela 3. Produção média de grãos, dos 20 genótipos de trigo avaliados em Capão Bonito, em condiçáo de sequeiro em solo corrigido e em solo ácido, no período 2006 a 2008

\begin{tabular}{|c|c|c|c|c|c|c|c|c|}
\hline \multirow{3}{*}{ Genótipos } & \multicolumn{4}{|c|}{ Capão Bonito (solo corrigido) } & \multicolumn{4}{|c|}{ Capão Bonito (solo ácido) } \\
\hline & 2006 & 2007 & 2008 & Média & 2006 & 2007 & 2008 & Média \\
\hline & \multicolumn{8}{|c|}{$\mathrm{kg} \mathrm{ha}^{-1}$} \\
\hline IAC-24 & $2.365 \mathrm{~b}-\mathrm{d}$ & $1.903 \mathrm{ab}$ & 1.167 & 1.811 & 913 a-e & $1.208 \mathrm{a}-\mathrm{c}$ & $1.042 \mathrm{a}-\mathrm{c}$ & 1.054 \\
\hline IAC-370 & $3.552 \mathrm{a}$ & $2.274 a b$ & 1.194 & 2.340 & 490 de & $1.021 \mathrm{bc}$ & 243 e & 584 \\
\hline 3 & $2.885 a-c$ & $1.997 \mathrm{ab}$ & 1.163 & 2.015 & 934 a-e & $1.351 \mathrm{a}-\mathrm{c}$ & 819 b-e & 1.035 \\
\hline 4 & $1.924 \mathrm{~d}$ & $2.535 \mathrm{ab}$ & 1.455 & 1.971 & 358 e & $806 \mathrm{c}$ & $281 \mathrm{de}$ & 481 \\
\hline 5 & $2.316 \mathrm{~b}-\mathrm{d}$ & $1.688 \mathrm{ab}$ & 1.340 & 1.781 & 802 a-e & $1.392 \mathrm{a}-\mathrm{c}$ & $990 \mathrm{a}-\mathrm{c}$ & 1.061 \\
\hline 6 & $3.160 \mathrm{ab}$ & $2.660 \mathrm{ab}$ & 1.372 & 2.397 & 837 a-e & $1.330 \mathrm{a}-\mathrm{c}$ & 569 c-e & 912 \\
\hline 7 & $2.497 \mathrm{~b}-\mathrm{d}$ & $1.556 a b$ & 1.556 & 1.869 & 809 a-e & $1.302 \mathrm{a}-\mathrm{c}$ & 875 a-d & 995 \\
\hline 8 & 2.299 b-d & $2.396 a b$ & 1.167 & 1.954 & 792 a-e & $1.184 a-c$ & $934 a-c$ & 970 \\
\hline 9 & $2.556 \mathrm{~b}-\mathrm{d}$ & $2.233 a b$ & 1.444 & 2.078 & $986 a-d$ & $1.333 \mathrm{a}-\mathrm{c}$ & $1.045 \mathrm{a}-\mathrm{c}$ & 1.122 \\
\hline 10 & $2.587 \mathrm{~b}-\mathrm{d}$ & $1.458 \mathrm{~b}$ & 1.392 & 1.813 & 819 a-e & $1.326 a-c$ & $1.063 \mathrm{a}-\mathrm{c}$ & 1.069 \\
\hline 11 & $2.837 a-c$ & $1.552 \mathrm{ab}$ & 1.503 & 1.964 & 819 a-e & $1.167 \mathrm{a}-\mathrm{c}$ & $903 a-c$ & 963 \\
\hline 12 & $1.906 \mathrm{~d}$ & $2.639 a b$ & 1.205 & 1.917 & $1.128 \mathrm{ab}$ & $1.528 \mathrm{ab}$ & 913 a-c & 1.190 \\
\hline 13 & $2.635 b-d$ & $2.385 a b$ & 1.653 & 2.225 & 819 a-e & $1.236 \mathrm{a}-\mathrm{c}$ & $1.295 \mathrm{ab}$ & 1.117 \\
\hline 14 & $2.451 \mathrm{~b}-\mathrm{d}$ & $1.878 \mathrm{ab}$ & 1.247 & 1.859 & 590 b-e & 1.094 bc & 625 c-e & 770 \\
\hline 15 & $2.590 \mathrm{~b}-\mathrm{d}$ & $2.319 \mathrm{ab}$ & 1.632 & 2.181 & $1.045 \mathrm{a}-\mathrm{d}$ & $1.281 \mathrm{a}-\mathrm{c}$ & 851 a-d & 1.059 \\
\hline 16 & $2.399 \mathrm{~b}-\mathrm{d}$ & $2.528 a b$ & 1.521 & 2.149 & 819 a-e & $1.326 a-c$ & $892 a-c$ & 1.013 \\
\hline 17 & $2.458 \mathrm{~b}-\mathrm{d}$ & $2.868 \mathrm{a}$ & 1.378 & 2.235 & $1.104 \mathrm{a}-\mathrm{c}$ & $1.715 \mathrm{a}$ & $965 a-c$ & 1.262 \\
\hline 18 & 2.444 b-d & $2.656 a b$ & 1.618 & 2.240 & 535 c-e & $1.247 \mathrm{a}-\mathrm{c}$ & 705 b-e & 829 \\
\hline 19 & $2.788 \mathrm{a}-\mathrm{d}$ & $2.076 \mathrm{ab}$ & 1.160 & 2.008 & $1.285 \mathrm{a}$ & $1.420 \mathrm{ab}$ & $969 a-c$ & 1.225 \\
\hline 20 & $2.260 \mathrm{~cd}$ & $2.302 \mathrm{ab}$ & 1.521 & 2.028 & $1.167 \mathrm{ab}$ & $1.583 a b$ & $1.444 \mathrm{a}$ & 1.398 \\
\hline F (Genótipos) & $4,93^{*}$ & $2,59^{*}$ & 1,23 & 0,81 & $4,38^{*}$ & $3,08^{*}$ & $6,35^{*}$ & $7,78^{*}$ \\
\hline$F($ Anos) & - & - & - & $57,58^{*}$ & - & - & - & $68,40^{*}$ \\
\hline$F(G \times A)$ & - & - & - & $3,49^{*}$ & - & - & - & $1,45^{*}$ \\
\hline d.m.s.(Tukey 5\%) & 897 & 1.356 & 814 & 702 & 589 & 592 & 599 & 569 \\
\hline C.V. (\%) & 13,43 & 23,53 & 22,40 & 18,41 & 26,34 & 17,46 & 26,18 & 22,24 \\
\hline
\end{tabular}

*Significativo ao nível de 5\%. Médias seguidas de uma letra em comum năo diferem, entre si, pelo teste de Tukey. 
Tabela 4. Estimativas dos parâmetros de adaptabilidade e estabilidade obtidos pelo método de Lin e Binns (1988), para produção de grãos $\left(\mathrm{kg} \mathrm{ha}^{-1}\right)$, dos 20 genótipos de trigo avaliados em Capão Bonito, no período de 2006 e 2008

\begin{tabular}{|c|c|c|c|c|c|c|c|}
\hline \multirow{2}{*}{ Genótipos } & Média & $\mathbf{P}_{\mathrm{ig}}$ & Classif. & $P_{\text {if }}$ & Classif. & $P_{\text {id }}$ & Classif. \\
\hline & & $10^{3}$ & & $10^{3}$ & & $10^{3}$ & \\
\hline IAC-24 & 1.433 & 261,12 & 14 & 585,04 & 15 & 99,15 & 12 \\
\hline IAC-370 & 1.462 & 259,96 & 13 & 88,20 & 2 & 345,84 & 19 \\
\hline 3 & 1.525 & 174,16 & 8 & 300,88 & 5 & 110,80 & 14 \\
\hline 4 & 1.227 & 486,55 & 20 & 690,31 & 16 & 384,67 & 20 \\
\hline 5 & 1.421 & 296,81 & 17 & 730,02 & 20 & 80,21 & 9 \\
\hline 6 & 1.655 & 115,87 & 1 & 49,23 & 1 & 149,18 & 16 \\
\hline 7 & 1.433 & 297,05 & 18 & 708,59 & 18 & 91,28 & 11 \\
\hline 8 & 1.462 & 234,50 & 11 & 448,19 & 11 & 127,66 & 15 \\
\hline 9 & 1.600 & 152,78 & 6 & 348,81 & 9 & 54,77 & 3 \\
\hline 10 & 1.441 & 291,75 & 16 & 729,83 & 19 & 72,71 & 7 \\
\hline 11 & 1.464 & 256,31 & 12 & 560,77 & 14 & 104,08 & 13 \\
\hline 12 & 1.553 & 275,33 & 15 & 690,43 & 17 & 67,78 & 5 \\
\hline 13 & 1.671 & 128,58 & 3 & 268,54 & 3 & 58,59 & 4 \\
\hline 14 & 1.314 & 324,71 & 19 & 548,07 & 13 & 213,03 & 18 \\
\hline 15 & 1.620 & 152,07 & 5 & 306,71 & 7 & 74,75 & 8 \\
\hline 16 & 1.581 & 177,96 & 9 & 361,25 & 10 & 86,32 & 10 \\
\hline 17 & 1.748 & 127,88 & 2 & 299,20 & 4 & 42,22 & 2 \\
\hline 18 & 1.534 & 216,78 & 10 & 318,15 & 8 & 166,10 & 17 \\
\hline 19 & 1.616 & 147,22 & 4 & 302,74 & 6 & 69,46 & 6 \\
\hline 20 & 1.713 & 169,86 & 7 & 497,40 & 12 & 6,10 & 1 \\
\hline
\end{tabular}

$\mathrm{P}_{\mathrm{ig}}$ : estimativa da adaptabilidade e estabilidade do cultivar i considerando os ambientes favoráveis e desfavoráveis; $\mathrm{P}_{\mathrm{if}}$ estimativa da adaptabilidade e estabilidade do cultivar i considerando o ambiente favorável; $\mathrm{P}_{\mathrm{id}}$ : estimativa da adaptabilidade e estabilidade do cultivar i considerando o ambiente desfavorável. Valores de $\mathrm{P}_{\mathrm{ig}}$, $\mathrm{P}_{\mathrm{if}}$ e $\mathrm{P}_{\mathrm{id}}$ divididos por 10.000 .

e 2008, revelou efeitos significativos para genótipos e não significativos para anos nos dois ambientes e para a interação GxA em condição de solo corrigido (Tabela 5).

Na média dos experimentos instalados em solo corrigido, verificou-se que a linhagem 3 exibiu plantas mais baixas $(59 \mathrm{~cm})$, não diferindo apenas da linhagem $18(68 \mathrm{~cm})$. Em solo ácido, no ano de 2007, a linhagem $18(55 \mathrm{~cm})$ com plantas mais baixas, não diferiu da cultivar IAC-370 e das linhagens 3, 4, 6, 9, 11, 17 e 19. Em 2008, a linhagem $6(48 \mathrm{~cm})$, com plantas baixas, diferindo das linhagens 8,9 , $10,12,13,15,16,19$ e 20. Entretanto, todos os genótipos são de porte semianão, com exceção da linhagem 3, de porte anáo (abaixo de $60 \mathrm{~cm}$ ) em condição de solo corrigido e solo ácido. Esse resultado era esperado considerando que os genitores utilizados nos cruzamentos que originaram as linhagens são de porte semianão, como também observado por CAmargo et al. (2008), avaliando linhagens oriundas de hibridaçôes em diferentes regiôes paulistas.

Comparando-se os dois ambientes, houve redução da altura das plantas de todos os genótipos em condição de solo ácido (ambiente desfavorável), resultados também observados por Felício et al. (2001). Entretanto, as linhagens 3 e 18 exibiram plantas mais baixas nos dois ambientes, revelando-se boas fontes genéticas para esse caráter.

As porcentagens médias de acamamento das 18 linhagens e das duas cultivares- controle avaliadas, em solo corrigido e solo ácido, estão listadas na tabela 5. Apesar das linhagens serem, de modo geral, de porte semianáo, verificou-se comportamento diferenciado quanto à porcentagem de plantas acamadas. As linhagens 4, 6, 7, 8, 10 e 18 exibiram as maiores porcentagens de plantas acamadas (variando de $40 \%$ a $60 \%$ ) nos dois ambientes, mais evidenciado em 2007, em condição de solo ácido. As linhagens 1, 2, 3, 9, 12, 14, 16 e 19 tiveram porcentagens máximas de 20\%. A linhagem 17 destacou-se das demais, nos dois ambientes, com apenas $6 \%$ de plantas acamadas, associada às plantas de porte semianão intermediário. A resposta dos genótipos evidencia que outros mecanismos genéticos, e não apenas a altura das plantas, também podem estar associados com a resistência ao acamamento, concordando com os resultados observados por CAMARGO et al. (2005). Por outro lado, a resistência demonstrada pelas linhagens 3 e 18, em condição de solo ácido, pode estar associada a plantas mais baixas nessas condiçóes.

$\mathrm{Na}$ tabela 6, são apresentadas as médias de incidência percentual de ferrugem-da-folha dos 20 genótipos avaliados em condição de solo corrigido e solo ácido, em 2006 a 2008. A incidência da doença foi considerada baixa nos seis experimentos, não ocorrendo danos à produção de grãos. Nas linhagem 12 foi a mais resistente ao agente causal da doença nas duas condiçóes ambientais do triênio. As linhagens 14 e 18, relativamente suscetíveis, os índices médios de infecção foram de $35 \%$ em, pelo menos, um experimento (Metha, 1993).

As análises de variância individuais e os testes de médias para comprimento da espiga, número de espiguetas por espiga, número de grãos por espiga, número de grãos por espigueta e massa de cem grãos, avaliados nas 18 linhagens e nas duas cultivares de trigo, em condição de solo ácido e solo corrigido, em 2008, estão na tabela 7. 
Tabela 5. Altura média das plantas dos 20 genótipos de trigo avaliados em Capão Bonito (CB.), em condição de sequeiro em solo corrigido (S.C.) e solo ácido e em Tatuí e Mococa, em condição de irrigação por aspersão e solo corrigido, no período de 2006 a 2008

\begin{tabular}{|c|c|c|c|c|c|c|c|c|c|c|}
\hline \multirow{4}{*}{ Genótipos } & \multicolumn{4}{|c|}{ Altura das plantas } & \multicolumn{6}{|c|}{ Acamamento } \\
\hline & \multirow{2}{*}{$\begin{array}{c}\text { CB. (S.C.) } \\
\text { Média }\end{array}$} & \multicolumn{3}{|c|}{ Capão Bonito (solo ácido) } & \multicolumn{3}{|c|}{ Capão Bonito (solo corrigido) } & \multicolumn{3}{|c|}{ Capão Bonito (solo ácido) } \\
\hline & & 2007 & 2008 & Média & 2007 & 2008 & Média & 2007 & 2008 & Média \\
\hline & \multicolumn{4}{|c|}{$\mathbf{c m}$} & \multicolumn{6}{|c|}{$\%$} \\
\hline IAC-24 & $73 \mathrm{~cd}$ & $66 \mathrm{a}-\mathrm{d}$ & $61 \mathrm{a}-\mathrm{c}$ & 64 & 10 & 10 & 10 & 20 & 10 & 15 \\
\hline IAC-370 & $78 \mathrm{a}-\mathrm{d}$ & 64 b-e & $58 \mathrm{a}-\mathrm{c}$ & 61 & 10 & 6 & 8 & 20 & 10 & 15 \\
\hline 3 & 59 e & $58 \mathrm{de}$ & 53 bc & 55 & 0 & 0 & 0 & 20 & 10 & 15 \\
\hline 4 & $80 a-c$ & 64 b-e & 53 bc & 58 & 10 & 10 & 10 & 50 & 10 & 30 \\
\hline 5 & $81 \mathrm{a}-\mathrm{c}$ & $70 \mathrm{a}-\mathrm{c}$ & $65 a-c$ & 68 & 30 & 20 & 25 & 30 & 20 & 25 \\
\hline 6 & $71 \mathrm{~cd}$ & 60 c-e & $48 c$ & 54 & 40 & 10 & 25 & 60 & 6 & 33 \\
\hline 7 & 78 a-d & $68 \mathrm{a}-\mathrm{d}$ & $63 a-c$ & 65 & 10 & 10 & 10 & 40 & 40 & 40 \\
\hline 8 & $84 a b$ & $73 a b$ & $73 a$ & 73 & 30 & 20 & 25 & 50 & 20 & 35 \\
\hline 9 & $73 \mathrm{~cd}$ & 64 b-e & $68 a b$ & 66 & 20 & 6 & 13 & 20 & 16 & 18 \\
\hline 10 & 77 b-d & $68 \mathrm{a}-\mathrm{d}$ & $73 a$ & 70 & 0 & 36 & 18 & 50 & 16 & 33 \\
\hline 11 & 76 b-d & 65 a-e & $60 a-c$ & 63 & 0 & 10 & 5 & 30 & 16 & 23 \\
\hline 12 & $81 \mathrm{a}-\mathrm{c}$ & $70 a-c$ & $74 \mathrm{a}$ & 72 & 0 & 6 & 3 & 20 & 10 & 15 \\
\hline 13 & $84 a b$ & $69 a-c$ & $70 a b$ & 69 & 10 & 10 & 10 & 30 & 16 & 23 \\
\hline 14 & $79 a-c$ & $68 \mathrm{a}-\mathrm{d}$ & $66 \mathrm{a}-\mathrm{c}$ & 67 & 0 & 0 & 0 & 20 & 10 & 15 \\
\hline 15 & $84 a b$ & $75 a$ & $76 a$ & 76 & 40 & 16 & 28 & 30 & 16 & 23 \\
\hline 16 & $88 \mathrm{a}$ & $75 a$ & $74 \mathrm{a}$ & 74 & 10 & 16 & 13 & 20 & 16 & 18 \\
\hline 17 & $73 \mathrm{~cd}$ & 61 c-e & $63 a-c$ & 62 & 0 & 6 & 3 & 0 & 0 & 0 \\
\hline 18 & $68 \mathrm{de}$ & 55 e & 54 bc & 54 & 0 & 0 & 0 & 50 & 10 & 30 \\
\hline 19 & $73 \mathrm{~cd}$ & 61 c-e & $68 a b$ & 64 & 10 & 20 & 15 & 20 & 16 & 18 \\
\hline 20 & 78 a-d & $74 a b$ & $75 a$ & 74 & 10 & 20 & 15 & 30 & 20 & 25 \\
\hline F Genótipos & $10,80^{*}$ & $7,22^{*}$ & $5,30^{*}$ & $710^{*}$ & - & - & - & - & - & - \\
\hline F Anos & 0,33 & - & - & 2,38 & - & - & - & - & - & - \\
\hline$F(G \times A)$ & 1,09 & - & - & $1,67^{*}$ & - & - & - & - & - & - \\
\hline d.m.s.(Tukey 5\%) & 11 & 11 & 19 & 20 & - & - & - & - & - & - \\
\hline C.V. (\%) & 6,90 & 6,31 & 11,48 & 8,50 & - & - & - & - & - & - \\
\hline
\end{tabular}

*Significativo ao nível de 5\%. Médias seguidas de uma letra em comum não diferem, entre si, pelo teste de Tukey.

Tabela 6. Graus médios de infecção de ferrugem-da-folha $\left(^{1}\right)$ dos 20 genótipos de trigo avaliados em Capão Bonito, em condiçấo de solo corrigido e solo ácido, no período 2006 a 2008

\begin{tabular}{|c|c|c|c|c|c|c|c|c|}
\hline \multirow[b]{2}{*}{ Genótipos } & \multicolumn{4}{|c|}{ Capão Bonito (solo corrigido) } & \multicolumn{4}{|c|}{ Capão Bonito (solo ácido) } \\
\hline & 2006 & 2007 & 2008 & Média & 2006 & 2007 & 2008 & Média \\
\hline & \multicolumn{8}{|c|}{$\%$} \\
\hline IAC-24 & $25 S$ & $15 S$ & 0 & $13 S$ & $8 S$ & $10 S$ & $10 \mathrm{~S}$ & 9S \\
\hline IAC-370 & $20 \mathrm{~S}$ & $5 S$ & 0 & $8 \mathrm{~S}$ & $8 \mathrm{~S}$ & $10 \mathrm{~S}$ & $11 S$ & $9 S$ \\
\hline 3 & $25 S$ & $3 S$ & 0 & 9S & $10 \mathrm{~S}$ & $10 \mathrm{~S}$ & $6 \mathrm{~S}$ & 9S \\
\hline 4 & $5 S$ & 0 & 0 & $2 S$ & 35 & $3 S$ & 0 & $2 S$ \\
\hline 5 & $8 \mathrm{~S}$ & $5 S$ & 0 & $4 S$ & 135 & $15 S$ & tS & 9S \\
\hline 6 & $10 \mathrm{~S}$ & 35 & 0 & $4 \mathrm{~S}$ & $6 \mathrm{~S}$ & $6 \mathrm{~S}$ & 0 & $4 S$ \\
\hline 7 & $8 \mathrm{~S}$ & $5 \mathrm{~S}$ & 0 & $4 \mathrm{~S}$ & $5 S$ & $8 S$ & $3 S$ & $5 S$ \\
\hline 8 & 135 & $10 \mathrm{~S}$ & 0 & $8 S$ & 35 & $5 S$ & 0 & 35 \\
\hline 9 & $5 \mathrm{~S}$ & $5 \mathrm{~S}$ & 0 & $3 S$ & 35 & $5 S$ & tS & $3 S$ \\
\hline 10 & $8 \mathrm{~S}$ & $\mathrm{tS}$ & 0 & 35 & $10 \mathrm{~S}$ & $8 S$ & $\mathrm{tS}$ & $6 \mathrm{~S}$ \\
\hline 11 & $10 \mathrm{~S}$ & $8 S$ & 0 & $6 S$ & 135 & $6 S$ & 35 & $7 S$ \\
\hline 12 & tS & 0 & 0 & 0 & tS & tS & 0 & tS \\
\hline 13 & $15 S$ & $8 \mathrm{~S}$ & tS & $8 \mathrm{~S}$ & $10 \mathrm{~S}$ & 35 & $5 S$ & $6 \mathrm{~S}$ \\
\hline 14 & $35 S$ & $20 \mathrm{~S}$ & 85 & $21 \mathrm{~S}$ & $20 \mathrm{~S}$ & $15 S$ & 135 & $16 \mathrm{~S}$ \\
\hline 15 & $15 \mathrm{~S}$ & $3 S$ & tS & $6 \mathrm{~S}$ & 35 & 35 & 0 & $2 S$ \\
\hline 16 & $15 \mathrm{~S}$ & $5 \mathrm{~S}$ & tS & $7 S$ & 35 & $5 S$ & tS & $3 S$ \\
\hline 17 & $25 S$ & $15 S$ & tS & $14 \mathrm{~S}$ & $15 S$ & 35 & $3 S$ & $7 S$ \\
\hline 18 & $35 \mathrm{~S}$ & $8 \mathrm{~S}$ & tS & $14 \mathrm{~S}$ & $3 S$ & $8 \mathrm{~S}$ & $8 \mathrm{~S}$ & $6 S$ \\
\hline 19 & $6 \mathrm{~S}$ & $3 S$ & 0 & $3 S$ & tS & tS & 35 & tS \\
\hline 20 & $8 \mathrm{~S}$ & $5 S$ & 0 & $4 S$ & $11 \mathrm{~S}$ & $5 S$ & $3 S$ & $6 \mathrm{~S}$ \\
\hline
\end{tabular}

(1) Avaliaçáo segundo escala proposta por MeнтA (1993), sendo $0=$ imune; $1 \%$ a $5 \%$ de área infectada $=$ resistente; $6 \%$ a $25 \%=$ moderadamente resistente; $26 \%$ a $50 \%=$ suscetível e $51 \%$ a $99 \%$ = altamente suscetível; $\mathrm{t}=$ traço (apenas algumas pústulas); $\mathrm{S}=$ reaçáo de suscetibilidade. 
Tabela 7. Comprimento da espiga, número de espiguetas por espiga, número de grãos por espiga e por espigueta e massa de cem grãos dos 20 genótipos de trigo avaliados em Capão Bonito, em solo corrigido (S.C.) e em solo ácido (S.A.), em 2008

\begin{tabular}{|c|c|c|c|c|c|c|c|c|c|c|}
\hline \multirow{3}{*}{ Genótipos } & \multicolumn{2}{|c|}{$\begin{array}{c}\text { Comprimento da } \\
\text { espiga }\end{array}$} & \multicolumn{2}{|c|}{ Espiguetas/espiga } & \multicolumn{2}{|c|}{ Grãos/espiga } & \multicolumn{2}{|c|}{ Grãos/espigueta } & \multicolumn{2}{|c|}{$\begin{array}{l}\text { Massa de cem } \\
\text { grãos }\end{array}$} \\
\hline & S.C. & S.A. & S.C. & S.A. & S.C. & S.A & S.C. & S.A. & S.C. & S.A. \\
\hline & \multicolumn{2}{|c|}{$\mathrm{cm}$} & \multicolumn{6}{|c|}{$n^{\circ}$} & \multicolumn{2}{|c|}{ g } \\
\hline IAC-24 & $7,7 \mathrm{i}$ & $6,8 \mathrm{~d}-\mathrm{g}$ & $17,6 a b$ & 16,5 bc & 39,4 b-e & $34,0 a b$ & $2,26 a b$ & $2,06 a b$ & 3,26 a-e & $3,13 c-f$ \\
\hline IAC-370 & $9,6 a b$ & 7,2 b-g & $16,8 \mathrm{ab}$ & 12,7 de & 42,4 a-e & 27,2 b-d & $2,53 \mathrm{ab}$ & $2,17 a b$ & 3,33 a-e & $3,12 c-f$ \\
\hline 3 & $8,7 \mathrm{c}-\mathrm{h}$ & 7,5 a-e & $18,2 a b$ & $16,6 \mathrm{bc}$ & 40,8 b-e & $31,9 a b$ & $2,25 \mathrm{ab}$ & $1,95 a b$ & $2,76 \mathrm{e}$ & 2,67 ef \\
\hline 4 & $8,6 c-i$ & $6,2 \mathrm{fg}$ & $15,2 b$ & $12,7 \mathrm{de}$ & 37,2 c-e & $21,8 d$ & $2,45 a b$ & $1,73 b$ & $3,96 \mathrm{a}$ & 3,38 b-e \\
\hline 5 & $9,9 \mathrm{a}$ & $8,3 a b$ & $19,1 a b$ & $16,1 \mathrm{bc}$ & 40,8 b-e & 30,8 a-d & $2,14 b$ & $1,93 a b$ & 3,45 a-e & $3,86 a-c$ \\
\hline 6 & $8,5 d-i$ & $6,6 \mathrm{~d}-\mathrm{g}$ & $15,8 b$ & $12,5 \mathrm{e}$ & 33,0 e & $22,2 \mathrm{~cd}$ & $2,12 b$ & $1,80 \mathrm{ab}$ & $3,80 \mathrm{a}-\mathrm{c}$ & $3,92 \mathrm{ab}$ \\
\hline 7 & $8,7 \mathrm{c}-\mathrm{h}$ & 7,2 b-g & $18,2 a b$ & $16,1 \mathrm{bc}$ & 44,1 a-d & $31,4 a-c$ & $2,43 a b$ & $1,96 \mathrm{ab}$ & 3,17 b-e & $3,21 b-f$ \\
\hline 8 & $9,7 a b$ & $8,5 \mathrm{a}$ & $19,0 a b$ & 17,6 a-c & 44,7 a-d & $33,8 \mathrm{ab}$ & $2,37 \mathrm{ab}$ & $1,95 a b$ & 3,12 b-e & 3,26 b-f \\
\hline 9 & $7,8 \mathrm{hi}$ & $6,0 \mathrm{~g}$ & $18,6 a b$ & $15,1 \mathrm{c}-\mathrm{e}$ & 42,8 a-d & $31,2 \mathrm{a}-\mathrm{d}$ & $2,32 \mathrm{ab}$ & $2,09 a b$ & 3,45 a-e & 3,72 a-d \\
\hline 10 & 9,3 a-d & 7,7 a-e & $17,7 \mathrm{ab}$ & 15,9 bc & 41,4 a-e & $35,2 \mathrm{ab}$ & $2,35 \mathrm{ab}$ & $2,23 a b$ & 3,40 a-e & 3,48 a-d \\
\hline 11 & $9,4 a-c$ & $7,4 a-f$ & $18,6 \mathrm{ab}$ & $15,7 \mathrm{~b}-\mathrm{d}$ & 41,0 b-e & $31,8 \mathrm{ab}$ & $2,22 a b$ & $2,04 a b$ & 3,48 a-e & 3,58 a-d \\
\hline 12 & 9,0 b-f & 7,6 a-e & $19,4 a b$ & 15,9 bc & 46,0 a-c & $33,8 \mathrm{ab}$ & $2,37 a b$ & $2,12 a b$ & 3,04 c-e & 3,20 b-f \\
\hline 13 & $7,8 \mathrm{hi}$ & $7,3 \mathrm{a}-\mathrm{f}$ & $17,0 a b$ & 16,4 bc & 35,9 de & $34,6 \mathrm{ab}$ & $2,12 \mathrm{~b}$ & $2,11 a b$ & $4,00 \mathrm{a}$ & $4,24 \mathrm{a}$ \\
\hline 14 & $8,0 \mathrm{~g}-\mathrm{i}$ & 6,5 e-g & $18,5 a b$ & 14,5 c-e & $47,2 \mathrm{ab}$ & $33,4 a b$ & $2,56 \mathrm{ab}$ & $2,32 \mathrm{a}$ & $2,95 \mathrm{de}$ & $2,51 \mathrm{f}$ \\
\hline 15 & 8,4 e-i & 7,0 c-g & $22,1 \mathrm{a}$ & $18,8 \mathrm{ab}$ & $51,1 \mathrm{a}$ & $37,9 \mathrm{a}$ & $2,33 a b$ & $2,02 \mathrm{ab}$ & $3,87 a b$ & 3,39 b-e \\
\hline 16 & $8,8 \mathrm{~b}-\mathrm{g}$ & 7,1 b-g & $19,0 \mathrm{ab}$ & 15,8 b-d & 42,0 a-e & 29,7 a-d & $2,22 a b$ & $1,88 \mathrm{ab}$ & $3,68 \mathrm{a}-\mathrm{d}$ & 3,77 a-d \\
\hline 17 & $8,9 b-f$ & $7,8 \mathrm{a}-\mathrm{d}$ & 14,5 b & $17,4 \mathrm{a}-\mathrm{c}$ & 42,8 a-d & $32,3 a b$ & $2,20 \mathrm{ab}$ & $1,85 \mathrm{ab}$ & 3,34 a-e & 3,40 b-e \\
\hline 18 & $8,5 \mathrm{~d}-\mathrm{i}$ & 6,5 e-g & $18,0 \mathrm{ab}$ & 14,8 c-e & $49,1 a b$ & $34,1 a b$ & $2,73 \mathrm{a}$ & $2,31 \mathrm{a}$ & $3,01 \mathrm{de}$ & $3,09 \mathrm{~d}-\mathrm{f}$ \\
\hline 19 & $8,2 \mathrm{f}-\mathrm{i}$ & 6,9 c-g & $18,1 \mathrm{ab}$ & 15,0 c-e & 40,9 b-e & $34,2 a b$ & $2,27 a b$ & $2,28 \mathrm{a}$ & 3,06 c-e & 3,25 b-f \\
\hline 20 & 9,1 a-e & 8,1 a-c & $22,4 \mathrm{a}$ & 19,9 a & 46,5 a-c & $38,9 \mathrm{a}$ & $2,08 \mathrm{~b}$ & $1,96 \mathrm{ab}$ & 3,47 a-e & 3,33 b-e \\
\hline F Repetições & 1,03 & 1,89 & $3,70^{*}$ & 1,76 & 2,17 & 1,98 & $2,87^{*}$ & 2,08 & 1,75 & 1,46 \\
\hline F Genótipos & $14,40^{*}$ & $7,21^{*}$ & $2,84^{*}$ & $9,62^{*}$ & $5,46^{*}$ & $5,53^{*}$ & $2,61^{*}$ & $2,72^{*}$ & $5,61^{*}$ & $9,48^{*}$ \\
\hline d.m.s.(Tukey 5\%) & 0,9 & 1,3 & 6,0 & 3,2 & 9,8 & 9,6 & 0,54 & 0,53 & 0,77 & 0,70 \\
\hline C.V. (\%) & 3,88 & 7,07 & 12,50 & 7,68 & 8,76 & 11,43 & 8,84 & 9,97 & 8,71 & 7,86 \\
\hline
\end{tabular}

*Significativo ao nível de 5\%. Médias seguidas de uma letra em comum não diferem, entre si, pelo teste de Tukey.

Os quadrados médios das análises de variância individuais revelaram presença de variabilidade genética para genótipos nos dois ambientes em todos os caracteres agronômicos avaliados. A linhagem $5(9,9 \mathrm{~cm})$ destacouse quanto ao comprimento da espiga, em solo corrigido, não diferindo da cultivar IAC-370 e das linhagens 8, 10, 11 e 20; a linhagem $8(8,5 \mathrm{~cm})$ com espigas mais compridas, em solo ácido, não diferiu das linhagens $3,5,10$, $11,12,13,17$ e 20.

Quanto ao número de espiguetas por espiga, destacaram-se, em solo corrigido, as linhagens 15 e 20, diferindo das linhagens 4, 6 e 17. Em solo ácido, destacou-se a linhagem 20 não diferindo das linhagens 8,15 e 17.

Para a variável número de grãos por espiga, a linhagem $15(51,1)$, em solo corrigido, e as linhagens $15(37,9)$ e $20(38,9)$, em condição de solo ácido, exibiram maior número de grấos por espiga, diferindo da cultivar IAC-24 e das linhagens 3, 4, 5, 6, 11, 13 e 19, em solo corrigido, e da cultivar IAC-370 e das linhagens 4 e 6 em solo ácido.

A linhagem $18 \mathrm{com}$ maior número de grãos por espigueta, em solo corrigido, diferiu das linhagens 5, 6, 13 e 20. Em solo ácido, as linhagens 14, 18 e 19 exibiram maior número de grãos por espigueta, diferindo apenas da linhagem 4 . Em relaçáo à massa de cem grãos, destacaramse as linhagens 4 (3,96 g) e 13 (4,00 g) em solo corrigido, diferindo das linhagens 3, 7, 8, 12, 14, 18 e 19. Em solo ácido, a linhagem 13 (4,24 g), de grãos mais pesados, não diferiu das linhagens 5, 6, 9, 10, 11 e 16 (Tabela 7).

A presença de variabilidade genética em relaçáo aos componentes da produção em trigo também foi observada por Biudes et al. (2007), Lobato et al. (2007) e CAmARgo et al. (2008). A identificação de linhagens promissoras tem sido importante em programas de melhoramento, pois podem ser utilizadas como fonte genética em blocos de cruzamento.

Houve reduçáo nos valores observados de todos os caracteres em condição de solo ácido, o que já era esperado, tendo em vista que a presença do alumínio tóxico na camada superficial interfere na absorção de nutrientes, prejudicando consequentemente o desenvolvimento das plantas.

Correlaçóes simples obtidas com base nos dados de 2008 revelaram associaçóes positivas e significativas entre a produção de grãos e altura das plantas $\left(0,352^{*}\right)$ e massa de cem grãos $\left(0,486^{*}\right)$, em solo corrigido, demonstrando que houve uma tendência dos genótipos mais produtivos demonstrarem as plantas mais altas e grãos mais pesados. Em solo ácido, observou-se que nos genótipos mais produtivos havia plantas de porte semianão mais alto $\left(0,512^{*}\right)$, espigas mais compridas $\left(0,441^{*}\right)$, maior número de espiguetas por espiga $\left(0,650^{*}\right)$, espigas mais férteis $\left(0,613^{*}\right)$ 
e grãos mais pesados $\left(0,364^{*}\right)$. Em genótipos com maior número de grãos por espigueta, notaram-se os grãos mais leves $\left(-0,237^{*}\right)$ em solo ácido.

Verificou-se que as cultivares IAC-24 e BH-1146 e as linhagens $3,7,8,11,12,17,19$ e 20 foram tolerantes à presença de $10 \mathrm{mg} \mathrm{L}^{-1}$ de $\mathrm{Al}^{3+}$, pois houve crescimento das raízes, após permanecerem 48 horas em soluções com tal concentração (Tabela 8). Na cultivar-controle Anahuac (sensível a $2 \mathrm{mg} \mathrm{L}^{-1}$ de $\mathrm{Al}^{3+}$ ), na linhagem 4 (sensível a $4 \mathrm{mg} \mathrm{L}^{-1} \mathrm{de}^{3+}{ }^{3+}$ ), na cultivar IAC-370, na linhagem 14 (sensíveis a $6 \mathrm{mg} \mathrm{L}^{-1} \mathrm{de} \mathrm{Al}^{3+}$ ) e nas linhagens 5, 6, 9, 10, 13, 16 e 18 (sensíveis a $10 \mathrm{mg} \mathrm{L}^{-1} \mathrm{de} \mathrm{Al}^{3+}$ ) observou-se sensibilidade com o aumento das concentraçóes de alumínio em solução nutritiva.

Tabela 8. Comprimento médio das raízes dos 20 genótipos de trigo em seis diferentes concentraçóes de alumínio (média de 4 repetições)

\begin{tabular}{lrrrrrr} 
& \multicolumn{7}{c}{ Concentração de alumínio (mg L-1) } \\
\cline { 2 - 7 } Genótipos & $\mathbf{0}$ & $\mathbf{2}$ & $\mathbf{4}$ & $\mathbf{6}$ & $\mathbf{8}$ & \multicolumn{1}{c}{$\mathbf{1 0}$} \\
\cline { 2 - 7 } IAC-24 & 92,8 & 52,7 & 38,5 & 25,6 & 11,9 & 9,4 \\
\hline IAC-370 & 114,1 & 17,1 & 1,0 & 0,0 & 0,0 & 0,0 \\
\hline 3 & 94,8 & 61,9 & 33,7 & 23,7 & 12,9 & 10,4 \\
\hline 4 & 106,0 & 11,8 & 0,0 & 0,0 & 0,0 & 0,0 \\
\hline 5 & 84,6 & 49,1 & 15,5 & 13,8 & 1,7 & 0,0 \\
\hline 6 & 108,3 & 76,1 & 37,0 & 20,0 & 11,4 & 0,0 \\
\hline 7 & 89,8 & 58,0 & 41,8 & 37,8 & 14,9 & 5,8 \\
\hline 8 & 103,2 & 64,5 & 36,4 & 21,5 & 13,4 & 6,6 \\
\hline 9 & 91,4 & 45,2 & 6,7 & 4,5 & 0,1 & 0,0 \\
\hline 10 & 85,2 & 38,2 & 20,5 & 6,8 & 1,5 & 0,0 \\
\hline 11 & 101,5 & 46,5 & 31,2 & 30,3 & 14,2 & 10,5 \\
\hline 12 & 104,1 & 52,2 & 37,7 & 16,0 & 7,2 & 3,3 \\
\hline 13 & 100,8 & 51,0 & 29,4 & 10,1 & 7,3 & 0,0 \\
\hline 14 & 98,7 & 35,5 & 1,1 & 0,0 & 0,0 & 0,0 \\
\hline 15 & 99,5 & 29,9 & 4,3 & 0,3 & 0,0 & 0,0 \\
\hline 16 & 92,0 & 52,6 & 30,3 & 18,1 & 1,8 & 0,0 \\
\hline 17 & 116,9 & 70,7 & 49,6 & 43,9 & 41,5 & 31,3 \\
\hline 18 & 97,9 & 44,8 & 20,1 & 4,5 & 10,6 & 0,0 \\
\hline 19 & 105,9 & 56,8 & 37,4 & 22,8 & 15,9 & 8,2 \\
\hline 20 & 92,8 & 56,1 & 35,9 & 14,0 & 6,7 & 3,9 \\
\hline BH-1146 & 108,5 & 78,8 & 57,7 & 49,1 & 42,1 & 24,4 \\
\hline Anahuac & 98,0 & 0,0 & 0,0 & 0,0 & 0,0 & 0,0 \\
\hline
\end{tabular}

Tabela 9. Estimativas das correlaçôes simples entre as produçôes de grãos e os comprimentos das raízes dos 20 genótipos de trigo nas diferentes concentrações de $\mathrm{Al}^{3+}$

\begin{tabular}{|lcc|}
$\begin{array}{l}\text { Concentrações de } \\
\mathbf{A l}^{3+} \text { em } \text { m L L }^{-1}\end{array}$ & $\begin{array}{c}\text { Capão Bonito } \\
\text { (Solo corrigido) } \\
\mathbf{2 0 0 6 / 2 0 0 8}\end{array}$ & $\begin{array}{c}\text { Capão Bonito } \\
\text { (Solo ácido) } \\
\mathbf{2 0 0 6 / 2 0 0 8}\end{array}$ \\
\hline 2 & 0,075 & $0,645^{*}$ \\
\hline 4 & $-0,036$ & $0,639^{*}$ \\
\hline 6 & $-0,116$ & $0,466^{*}$ \\
\hline 8 & 0,154 & 0,405 \\
\hline 10 & 0,020 & 0,394 \\
\hline
\end{tabular}

* Significativo, ao nível de 5\%, pelo teste t.
Apesar do comportamento diferenciado das linhagens na presença das diferentes concentrações de alumínio tóxico, a elevada tolerância a esse elemento observada em laboratório poderia explicar a ausência de efeito significativo entre os dois ambientes. No entanto, na cultivar IAC-370 e nas linhagens 4 e 14 observaram-se reduçóes significativas na produtividade quando avaliadas em solo ácido, coerentemente com a sensibilidade ao alumínio demonstrada em soluçáo nutritiva.

As correlaçôes simples calculadas entre as produçôes médias de grãos, considerando os três anos em condição de solo corrigido e solo ácido e os comprimentos médios das raízes, são apresentadas na tabela 9. As correlaçôes foram positivas e significativas entre a produção de grãos e as concentraçóes de 2 , 4 e $6 \mathrm{mg} \mathrm{L}^{-1}$ de $\mathrm{Al}^{13+}$, demonstrando que os genótipos mais adaptados (mais produtivos) às condiçóes de solo ácido e ao cultivo de sequeiro foram tolerantes até a concentraçáo de $6 \mathrm{mg} \mathrm{L}^{-1}$ de $\mathrm{Al}^{3+}$. Resultados similares foram obtidos por CAMARgo et al. (2008) que observaram associação entre os genótipos mais resistentes ao alumínio em laboratório e os de melhor desempenho em solo ácido.

Não houve correlaçáo significativa entre a produçáo média de grãos e o crescimento médio das raízes em condiçấo de solo corrigido (Tabela 9). Esses resultados demonstraram que os genótipos mais adaptados às condiçôes de solo corrigido com calcário independeram do grau de tolerância à toxicidade de $\mathrm{Al}^{3+}$, em soluçôes nutritivas, resultados também relatados por Loвato et al. (2005).

\section{CONCLUSÃO}

As linhagens 13 e 17 , tolerantes ao $\mathrm{Al}^{3+}$ são de ampla adaptabilidade e estabilidade para produção de grãos, com perspectivas favoráveis na participação em programas de melhoramento visando ao aumento de massa dos grãos e à resistência ao acamamento respectivamente. A cultivar IAC-370 e a linhagem 6 , tolerantes a 4 e $8 \mathrm{mg} \mathrm{L}^{-1} \mathrm{de}^{3+}$, são responsivas à melhoria do ambiente. A linhagem 20 destaca-se não só por sua tolerância ao $\mathrm{Al}^{3+}$, mas também pela adaptaçáo a ambientes desfavoráveis e pelo número de espiguetas por espiga. A linhagem 12 é resistente ao agente causador da ferrugem-da-folha. A linhagem 15 demonstra maior número de espiguetas e grāos por espiga. As linhagens 5 e 8 têm espigas maiores e a linhagem 18, possui maior número de grãos por espigueta.

Os genótipos mais produtivos nas condiçôes de solo ácido possuem plantas mais altas, espigas mais compridas e férteis com grãos mais pesados, além de serem os mais tolerantes nas concentrações de 2 a $6 \mathrm{mg} \mathrm{L}^{-1}$ de alumínio, em solução nutritiva. Em condição de solo corrigido, há uma associação entre produção de grãos com altura das plantas e massa de grãos. 


\section{AGRADECIMENTOS}

Ao Conselho Nacional de Desenvolvimento Científico e Tecnológico - CNPq, pela concessão de auxílio à pesquisa e de bolsa de produtividade em pesquisa e à Fundação de Amparo à Pesquisa do Estado de São Paulo - FAPESP, pelo apoio financeiro.

\section{REFERÊNCIAS}

ALLARD, R.W. Principles of plant breeding. 2.ed. New York: John Wiley, 1999. 254p.

AMORIM, E.P.; CAMARGO, C.E.O.; FELÍCIO, J.C.; FERREIRA FILHO, A.W.P.; PETTINELLI JÚNIOR, A.; GALLO, P.B.; AZEVEDO FILHO, J. A. Adaptabilidade e estabilidade de linhagens de trigo no Estado de São Paulo. Bragantia, v.65, p.575$582,2006$.

BARROS, B.C.; CASTRO,J.L.; PATRICIO, J.R.A. Resposta de cultivares de trigo ao controle químico das principais doenças fúngicas. Summa Phytopathologica, v.31, p. 45, 2005.

BIUDES, G.B.; CAMARGO, C.E.O., FERREIRA FILHO, A.W.P.; AZEVEDO FILHO, J.A. Desempenho de genótipos de trigo introduzidos do México no Estado de São Paulo, Bragantia, v.66, p.403-411, 2007.

BIUDES, G.B.; CAMARGO, C.E.O., FERREIRA FILHO, A.W.P.; PETTINELLI JÚNIOR, A.; FOLTRAN, D.E.; CASTRO, J.L.; AZEVEDO FILHO, J.A. Adaptabilidade e estabilidade de linhagens diaplóides de trigo. Bragantia, v.68, p.63-74, 2009.

CAMARGO, C.E.O.; FELÍCIO, J.C.; TULMANN NETO, A.; FERREIRA FILHO, A.W.P.; PETTINELLI JÚNIOR, A.; CASTRO, J.L. Melhoramento de trigo: XXVIII. Novos genótipos obtidos por seleçôes em população segregante interespecífica submetida à irradiação gama. Bragantia, v.54, p.51-65, 1995.

CAMARGO, C.E.O., FERREIRA FILHO, A.W.P.; FELÍCIO, J.C.; GALLO, P.B.; LOBATO, M.T.V.; BIUDES, G.B. Desempenho de linhagens de trigo, oriundas de hibridaçôes, em duas condiçôes de cultivo do Estado de Sáo Paulo e tolerância à toxicidade de alumínio em laboratório. Bragantia, v.67, p.613-625, 2008.

CAMARGO, C.E.O., FERREIRA FILHO, A.W.P.; FELÍCIO, J.C.; RAMOS, L.C.S.; PETTINELLI JÚNIOR, A.; FOLTRAN, D.E.; CASTRO, J.L.; LOBATO, M.T.V. Linhagens diaplóides de trigo: desempenho agronômico em dois locais do Estado de Sáo Paulo e tolerância à toxicidade de alumínio em laboratório. Bragantia, v. 65, p.253-268, 2006.

CAMARGO, C.E.O., FERREIRA FILHO, A.W.P.; TULMANN NETO, A.; PETTINELLI JÚNIOR, A.; CASTRO, J.L.; FELÍCIO, J.C.; MISTRO, J.C.; SALOMON, M.V. Avaliação de linhagens de trigo originárias de hibridação com e sem irradiação gama. Bragantia, v. 64, p.71-74, 2005.

CARNEIRO, P.C.S. Novas metodologias de análise da adaptabilidade e estabilidade de comportamento. 1998. 168f. Tese (Doutorado) - Universidade Federal de Viçosa, Viçosa.

CHAVES, M.S.; BARCELLOS, A.L. Especialização fisiológica de Puccinia triticina no Brasil em 2002. Fitopatologia Brasileira, v.31, p. 57-62, 2006.

CRUZ, C.D. Programa Genes: versão Windows : biometria. Viçosa: UFV, 2006. 381p.

CRUZ, C.D.; REGAZZI, A.J.; CARNEIRO, P.C.S. Modelos biométricos aplicados ao melhoramento de plantas. 3.ed. Viçosa: UFV, 2004. 480p.

FALCONER, D.S.; MAKAY, T. F.C. Introduction to quantitative genetics. 4.ed. Harlow: Longman, 1996. 464p.

FELÍCIO, J.C.; CAMARGO, C.E.O., FERREIRA FILHO, A.W.P.; GALLO, P.B. Avaliação de genótipos de triticale e trigo em ambientes favoráveis e desfavoráveis no Estado de São Paulo. Bragantia, v.60, p.83-91, 2001.

KIM, B.Y.; BAIER, A.C.; SOMERS, D.J.; GUSTAFSON, J.P. Aluminium tolerance in triticale, wheat and rye. Euphytica, v.120, p.329-337, 2001.

LIN, C.S.; BINNS, M.R. A superiority measure of cultivar performance for cultivar $\mathrm{x}$ location data. Canadian Journal of Plant Science, v.68, p.193-198, 1988.

LOBATO, M.T.V.; CAMARGO, C.E.O.; FERREIRA FILHO, A.W.P.; BARROS, B.C.; CASTRO, J.L.; GALLO, P.B. Avaliação de linhagens de trigo provenientes de cruzamentos interespecíficos em dois locais do Estado de Sáo Paulo e em laboratório. Bragantia, v.66, p.31-41, 2007.

LOBATO, M.T.V.; CAMARGO, C.E.O.; FERREIRA FILHO, A.W.P.; BARROS, B.C.; PETTINELLI JÚNIOR, A.; PEREIRA, J.C.V.N.A.; GALLO, P.B. Desempenho de linhagens de trigo mexicanas, em condição de irrigação por aspersão no Estado de São Paulo. Arquivos do Instituto Biológico, v.72, p.211-219, 2005.

METHA, Y.R. Manejo integrado de enfermidades del trigo. Santa Cruz de la Sierra: Imprenta Landivar, S. R. L., 1993. 314p.

ROSA, O.S.; CAMARGO, C.E.O.; RAJARAM, S.; ZANATTA, A.C.A. Produtividade de trigo (Triticum aestivum (L.) THELL) com tolerância ao alumínio tóxico do solo. Pesquisa Agropecuária Brasileira, v.29, p. 411-417, 1994.

TULMANN NETO, A.; ALVES, M.C.; CAMARGO, C.E.O.; CASTRO, J.L..; FERREIRA FILHO, A.W.P. New wheat (Triticum aestivum $\mathrm{L}$.) genotypes tolerant to aluminum toxicity obtained by mutation breeding. Pesquisa Agropecuária Brasileira, v.36, p. 6170, 2001. 